Int. J. Dev. Biol. 52: 37-43 (2009)

doi: $10.1387 /$ ijdb.072542ja

\title{
Loss of REEP4 causes paralysis of the Xenopus embryo
}

\author{
JOANNA ARGASINSKA\#, AMER A. RANA\#, MICHAEL J. GILCHRIST, KIM LACHANI, ALICE YOUNG \\ and JAMES C. SMITH*
}

Wellcome Trust/Cancer Research UK Gurdon Institute and Department of Zoology, University of Cambridge, Cambridge, U.K.

\begin{abstract}
Members of the REEP (Receptor expression enhancing protein) family contain a TB2/ DP1, HVA22 domain that is involved in intracellular trafficking and secretion. Consistent with the presence of this domain, REEP1 and REEP3 enhance the expression of odorant and taste receptors in mammals, while mutation of these genes causes defects in neural development. REEP4 was identified in the course of a functional antisense morpholino oligonucleotide screen searching for genes involved in the early development of Xenopus tropicalis: although over-expression of the gene causes no phenotype, embryos lacking REEP4 develop a slightly kinked body axis and are paralysed. At tailbud stages of development, REEP4 is expressed in the somites and neural tube. The paralysis observed in embryos lacking REEP4 might therefore be caused by defects in the nervous system or in muscle. To address this point, we examined the expression of various neural and muscle markers and found that although all are expressed normally at early stages of development, many are down regulated by the tailbud stage. This suggests that REEP4 plays a role in the maintenance of both the nervous system and the musculature.
\end{abstract}

KEY WORDS: Xenopus, REEP4, neural, muscle

\section{Introduction}

REEP4 (Receptor expression enhancing protein 4) is a member of a family of transmembrane proteins which shares homology with the plant stress-induced gene HVA22 (Brands and Ho, 2002) and with yeast Yop1p (Calero et al., 2001). Yop1p is a membrane protein involved in Rab-mediated vesicle transport and is thought to regulate vesicle trafficking between the endoplasmic reticulum and the Golgi network. Mutations in REEP1 are thought to be responsible for hereditary spastic paraplegia in which the long axons of motor neurons degenerate (McDermott et al., 2000, Zuchner et al., 2006) and REEP3 has been identified as a novel candidate gene underlying autism (Castermans et al., 2007). The molecular basis of these phenotypes is unclear, but we note that both REEP1 and REEP3 can increase the surface expression of chemoreceptor and $\mathrm{G}$ proteincoupled odorant receptors (Behrens et al., 2006, Saito et al., 2004). Indeed, the widespread expression of both REEP1 and REEP3 (Behrens et al., 2006) suggests that these factors might serve a general role in the folding and trafficking of transmembrane proteins.

Inhibition of REEP4 function in Xenopus tropicalisusing antisense morpholino oligonucleotides causes embryos to develop with a slightly kinked body axis and to be unable to move (Rana etal., 2006). In this study we analyse the expression pattern of REEP4 during early Xenopus development and characterise the effects of loss of REEP4 function on the expression of various neural and muscle markers. We conclude that loss of REEP4 causes defect in both muscle and neural development.

\section{Results}

\section{The Xenopus REEP proteins}

A Xenopus tropicalis REEP4 cDNA was obtained from an $X$. tropicaliscDNA library constructed using RNA derived from unfertilised eggs (clone identifier Tegg010a23; accession number CR926301) (Gilchrist et al., 2004). An X. laevis REEP4 cDNA was identified by BLAST searching (accession number NM_001093429) and obtained from the I.M.A.G.E. Consortium (ID6862296). Comparison of Xenopus, human and mouse REEP4, using NCBI BLAST search

Abbreviations used in this paper: MO, morpholino oligonucleotides; REEP, receptor expression enhancing protein.

\footnotetext{
*Address correspondence to: Jim Smith. Wellcome Trust/Cancer Research UK Gurdon Institute, Tennis Court Road, Cambridge CB2 1QN, UK. e-mail jim@gurdon.cam.ac.uk
}

"Note: JA and AAR contributed equally to this work.

Electronic Supplementary Material for this article consisting of 2 movies is available at: http://dx.doi.org/10.1387/ijdb.072542ja 
A

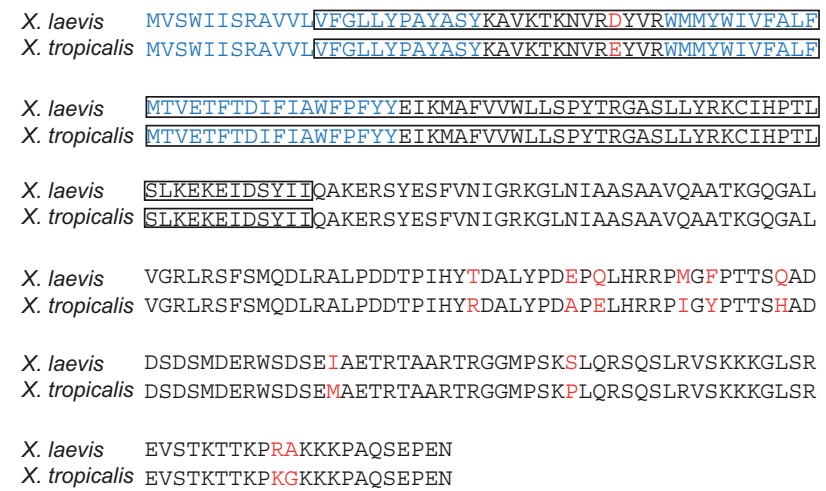

B

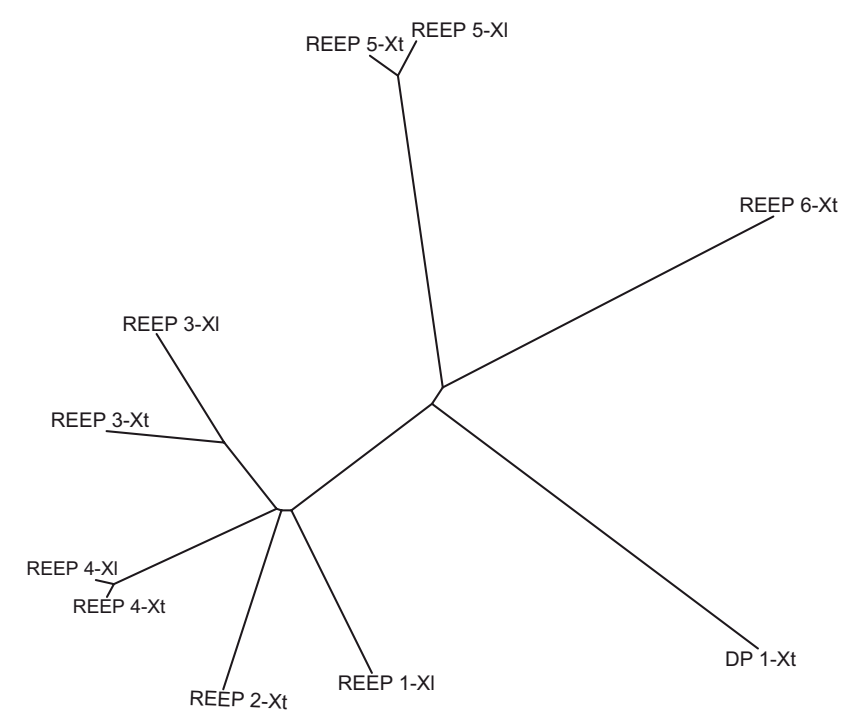

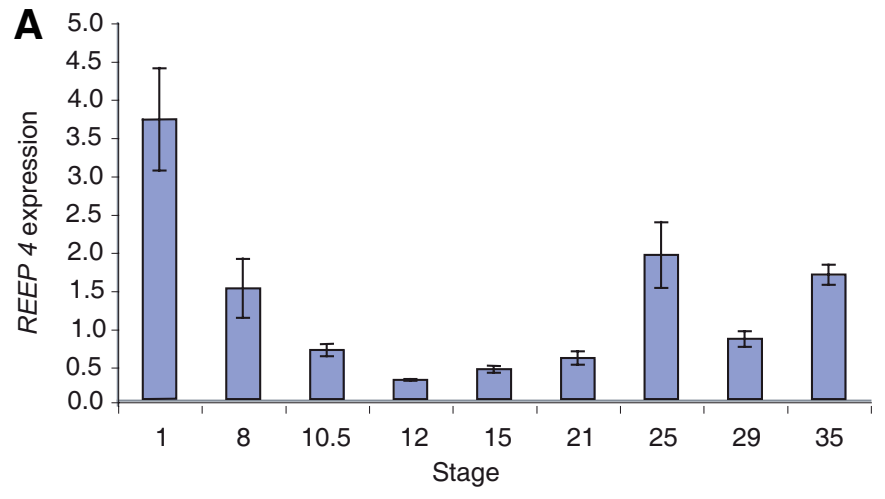
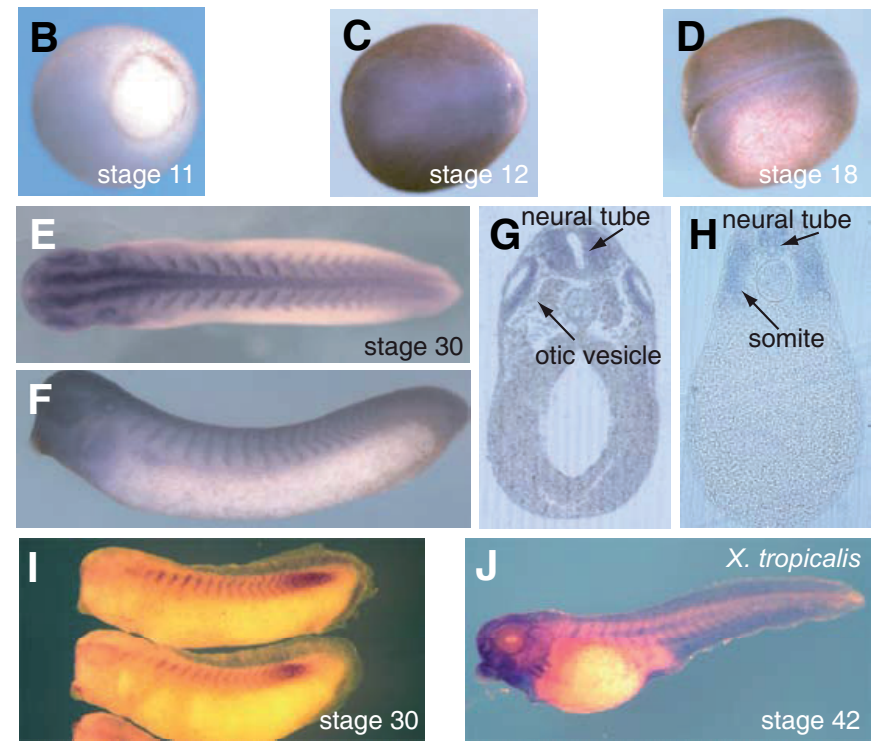

Fig. 1 (Left). Characterisation of Xenopus REEP4 and the REEP family. (A) Amino acid sequence comparison of Xenopus laevis and Xenopus tropicalis REEP4. Putative transmembrane regions are shown in blue, the first of which might function as a signal peptide. Differences between the sequences are shown in red. The TB2/DP1/HVA22 domain is boxed. (B) Unrooted phylogenetic tree of REEP family members. X. laevis: REEP1 BJ060675, REEP3 CA981706 (IMAGE:6868258), REEP4 NM_001093429 (IMAGE:6862296), REEP5 CD301868 (IMAGE:6958416). X. tropicalis: REEP2 Xt6.1-CAAM15596.5 (IMAGE:7685798), REEP3 Xt6.1-CAAN8638.5 (IMAGE:7694377), REE 4 Xt6.1-CABJ495.5.5 TEgg068f10 (CR926301.2), REEP5 Xt6.1-CABD4546.3 TNeu028a23 (CR761929.2), REEP6 Xt6.1-EC2CAA1AG10.3 (CT025233.2), DP1 Xt6.1-TTbA078015.5.5 TEgg014C10 (CR762038.2).

Fig. 2 (Right). Expression pattern of Xenopus REEP4. (A) RT-PCR based expression profile of X. laevis REEP4 from stage 1 to tailbud stage 35. Values have been normalized to those of ornithine decarboxylase (ODC). (B-F) Whole-mount in situ hybridisation analysis of X. laevis REEP4 expression. (G-H) Transverse sections of X. laevis embryos at stage 30. Note expression of REEP4 in neural tube, otic vesicles and somites. (I,J) Expression of X. tropicalis REEP4 at tailbud stage 30 and tadpole stage 42. Note strong expression in somites in (I) and in the nervous system in (J). $(\mathbf{K}, \mathbf{L})$ REEP4 localises to plasma and nuclear membranes. Embryos at the one-cell stage were left uninjected (J) or received injections of 2 ng RNA encoding C-terminally GFP-tagged REEP4 (I). They were examined at stage 15. Note presence of tagged REEP4 in nuclear and plasma membranes.

(Altschul etal., 1997), showed that REEP4 is highly conserved within these vertebrates. $X$. tropicalis and $X$. laevis REEP4 share $95 \%$ identity (Fig. 1A), while human and mouse, respectively, share $69 \%$ and $67 \%$ identity with $X$. tropicalis REEP4.

All REEP proteins contain a conserved TB2/DP1, HVA22 domain near their N-termini (Fig. 1A). The TB2/DP1, HVA22 family (Pfam PF03134) includes members from a wide variety of eukaryotes, such as human TB2/DP1 (deleted in polyposis) (Lal and Gallinger, 2000) and the plant abscisic acid-induced regulatory protein HVA22 (Shen et al., 1993). The REEP proteins are orientated with their C-termini outside of the cell, and may play a general role in permitting cellsurface expression of G-protein coupled receptors (Clark et al.,
2005). We note that REEP4 contains two putative transmembrane domains, the first of which might serve as a signal peptide (Saito et al., 2004) (Fig. 1A).

The human and mouse genomes contain at least five genes homologous to REEP4 (REEPs1-3 and REEPs5 and 6). We have identified the Xenopus homologues of these proteins and constructed the unrooted phylogenetic tree of all currently known Xenopus REEP family members (Fig. 1B).

\section{REEP4 expression pattern}

The expression and function of REEP4 was examined in both $X$. laevis and $X$. tropicalis. Real time RT-PCR carried out on RNA 
extracted from embryos of $X$. laevis reveals, as in $X$. tropicalis(Rana et al., 2006), that there is significant maternal expression of REEP4, after which levels decline during cleavage stages and gastrulation. Transcription then increases during neurula and tailbud stages (Fig. 2A). In situ hybridisation of $X$. laevis embryos shows that during gastrulation REEP4 is expressed on the dorsal side of the embryo (Fig. 2B) and then in the neural plate and neural tube (Fig. 2C,D). At tailbud stages (Fig. 2E-H) REEP4 is expressed in the somites (Fig. 2E,F,H), neural tube (Fig. 2G,H) and otic vesicle (Fig. 2G).

At early stages REEP4 expression in $X$. tropicalis resembles that in $X$. laevis (data not shown) but at tailbud stages transcription predominates in the somites (Fig. 2l), with neural expression being activated only later (Fig. 1J).

Overexpression of REEP4 in both $X$. laevis and $X$. tropicalis had no significant effect on development (data not shown).

\section{Depletion of REEP4 in both X. tropicalis and X. laevis causes paralysis and shortening of the body axis}

REEP4 loss-of-function embryos were created by use of antisense morpholino oligonucleotides (MOs). Two non-overlapping REEP4 MOs were designed for $X$. tropicalis (Rana et al., 2006) (Fig. 3A) and one for X. laevis (Fig. 3A). X. tropicalis MO1 and the $X$. laevis $\mathrm{MO}$ spanned the initiation codons of their target mRNAs; the second $X$. tropicalis $\mathrm{MO}(\mathrm{MO} 2)$ targeted sequence that is 5' of MO1. Both $X$. tropicalis MOs inhibited translation of REEP4 in an in vitro transcription-translation reaction (Fig. 3B, left), with $\mathrm{MO} 2$ being more effective than $\mathrm{MO} 1$ (Fig. 3B, left). The $X$. laevis $\mathrm{MO}$ inhibited translation of mRNA encoding $\mathrm{HA}$-tagged REEP4 following injection into the Xenopus embryo at the one- cell stage (Fig. 3B, right).

$X$. tropicalisembryos were injected at one cell stage with $30 \mathrm{ng}$ of $\mathrm{MO} 1$ or $\mathrm{MO} 2$ and $X$. laevis embryos were injected with $90 \mathrm{ng}$ MO. Loss of REEP4 function caused similar phenotypes in both species, although $X$. tropicalis $\mathrm{MO} 2$ gave a stronger phenotype than did $X$. tropicalis MO1, an observation consistent with data suggesting that $\mathrm{MO} 2$ is more effective in inhibiting translation of REEP4 mRNA (Fig. 3B, left). Thus, embryos appeared normal at gastrula stages (not shown) but by the tailbud stage there appeared to be some delay in development compared with embryos injected with control MO (Fig. 3C,D,G,H). For example, in $X$. tropicalis, 35 out of 49 cases resembled the top embryo in Fig. $3 \mathrm{H}$ and the remaining 14 resembled the lower two embryos. In addition, embryos injected with MOs directed against REEP4 frequently displayed a slightly bent antero-posterior axis and their posterior structures were reduced. Significantly, unlike control embryos, such embryos were unable to move in response to touch (see Supplementary movie).

The similarity of the $X$. laevis and $X$. tropicalis phenotypes indicates that the effects of our antisense MOs are specific. To confirm this suggestion, we attempted to 'rescue' the phenotypes. In the first series of experiments, $X$. laevis embryos were coinjected with $90 \mathrm{ng}$ REEP4 MO together with $2 \mathrm{ng}$ RNA encoding $X$. tropicalis GFP-tagged REEP4. There are five base mis-matches between $X$. tropicalisREEP4 mRNA and the $X$. laevisREEP4 MO, so the two are unlikely to form stable hybrids (Rana et al., 2006). $X$. tropicalis REEP4 proved to rescue the effects of the $X$. laevis $\mathrm{MO}$, both morphologically (Fig. 3D,E) and quantitatively, as judged by the lengths of control MO, REEP4 MO and 'rescued'
Fig. 3. Inhibition of translation of $X$. laevis and $X$. tropicalis REEP4 by antisense morpholino oligonucleotides. (A) Positions of X. tropicalis MO1 and MO2 and X. laevis $\mathrm{MO}$ are indicated in red. The start codon of each open reading frame is shown in blue. (B) Left panel: X. tropicalis REEP4 MO1 and MO2 inhibit translation of REEP4 $m R N A$ in an in vitro transcription-translation reaction. MOs were used at concentrations of 5, 2.5 and $1 \mu \mathrm{M}$. Right panel: X. laevis REEP4 MO (90 ng) inhibits translation of REEP4-HA mRNA. The indicated amounts of REEP4 mRNA were injected into embryos of $\mathrm{X}$. laevis at the one-cell stage in the presence or absence of MO. They were cultured to gastrula stage 11 and then processed for Western blotting. (C-I) Rescue of the effects of REEP4 antisense morpholino oligonucleotides. (C-F) Experiments in X. laevis. Embryos were injected with 90 ng control MO (C), 90 ng REEP4 MO (D) or 90 ng REEP4 MO together with 2 ng $m R N A$ encoding $\mathrm{X}$. tropicalis REEP4-HA. There are five base mis-matches between the $\mathrm{X}$. laevis $\mathrm{MO}$ and $X$. tropicalis REEP4. Note the morphological rescue of the REEP4 MO phenotype in (E). (F) Measurements of the lengths of embryos cultured to stage 32 after injection with 90 ng control MO, REEP4 MO, orREEP4 MO together with mRNA encoding $\mathrm{X}$. tropicalis REEP4-HA confirm the ability of REEP4 mRNA to rescue the REEP4 MO phenotype. *Indicates a significant difference in axis length between control MO and REEP4 MO, and between Rescue and REEP4 MO (Student's t, $P<0.0001)$. (G-I) Rescue experiments performed in $\mathrm{X}$. tropicalis. Embryos were injected with $30 \mathrm{ng}$ control MO (G) or MO2 (H) or with 30 ng MO2 together with 1.2 ng RNA encoding REEP4-GFP (I).
A

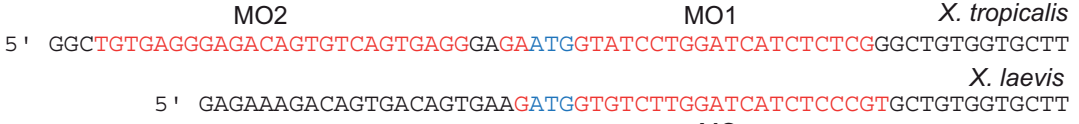
$\mathrm{MO}$

B
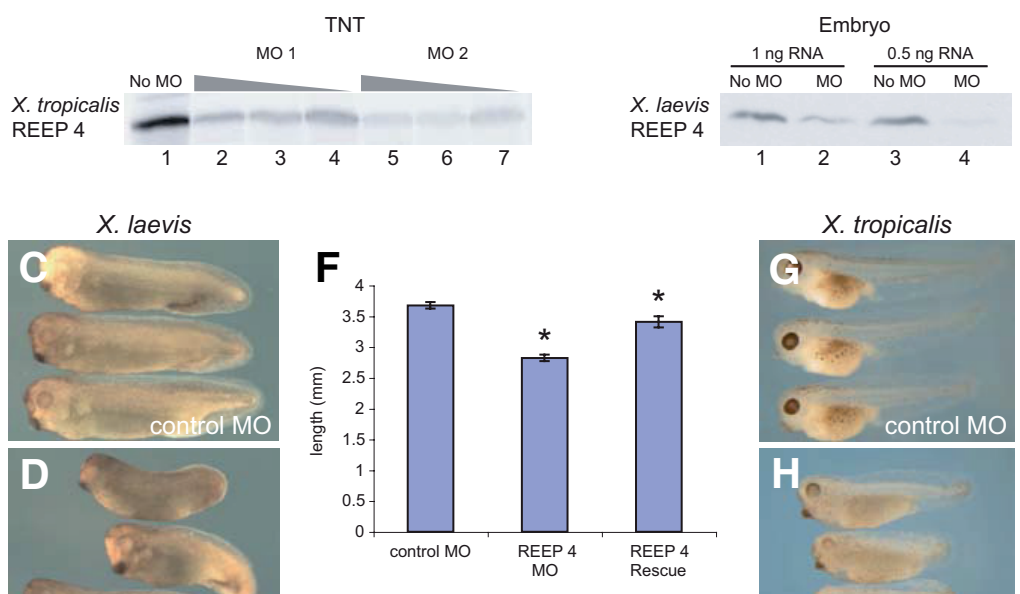

D

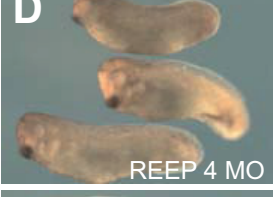

$\mathrm{H}$
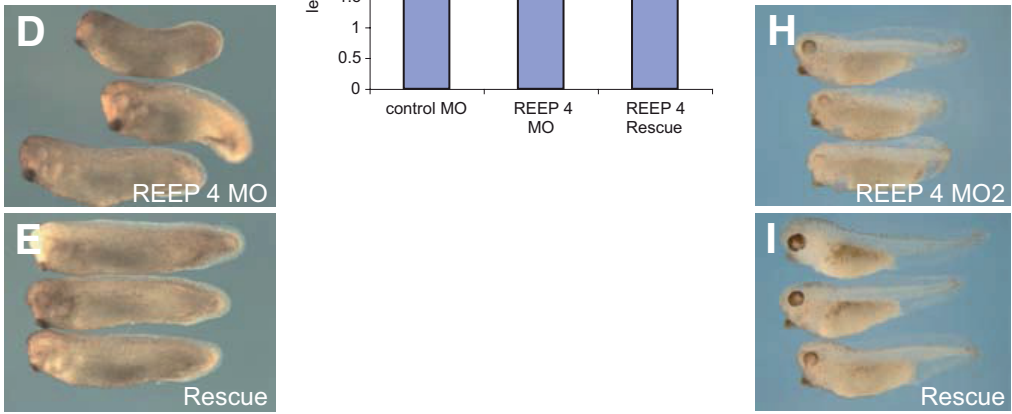


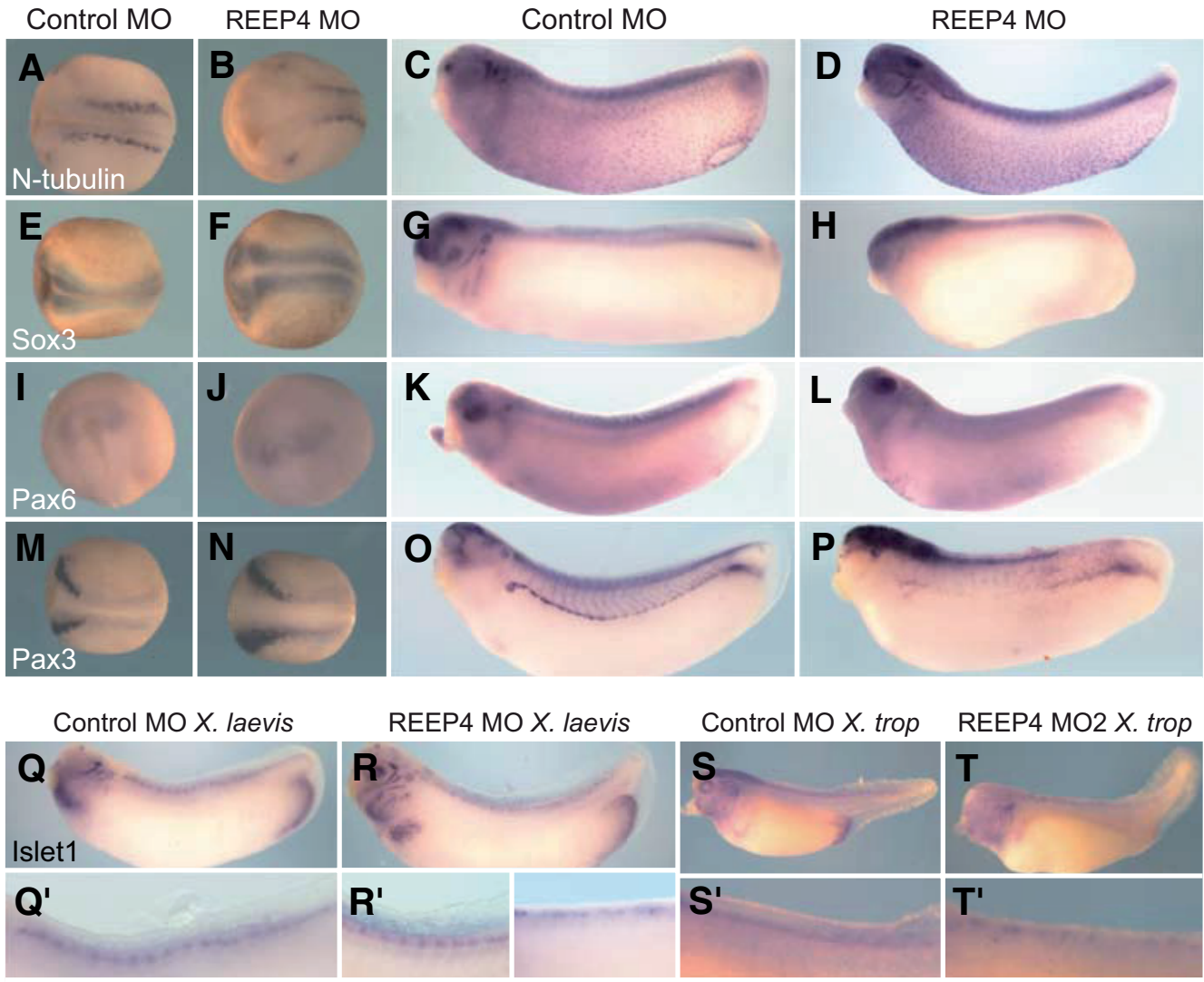

Fig. 4. Expression of neural markers in embryos lacking REEP4 function. $X$. laevis or $X$. tropicalis embryos were injected, respectively, with $90 \mathrm{ng} \mathrm{MO}$ or $30 \mathrm{ng} \mathrm{MO2}$. Control embryos received the same amounts of control MO. They were cultured to neurula (stage 15-18) or tailbud (stage 29/30) stages and analysed by in situ hybridisation for expression of N-tubulin, Sox3, Pax6 and Pax3. Expression of the neural markers N-tubulin, Sox3 and Pax6 is normal in embryos of $\mathrm{X}$. laevis at neurula stages (A,B; $\mathbf{E}, \mathbf{F} ; \mathbf{I}, \mathbf{J})$ and has declined little by tailbud stages (C,D; $\mathbf{G}, \mathbf{H} ; \mathbf{K}, \mathbf{L})$. Early expression of the neural crest marker Pax3 is little affected by loss of REEP4 function $(\mathbf{M}, \mathbf{N})$, but expression in somites and pronephros becomes disrupted at tailbud stages $(\mathbf{O}, \mathbf{P})$. More prolonged culture to stage 38 (Q-T) reveals that Islet1 expression becomes disrupted in embryos lacking REEP4. Thus, in embryos of X. laevis, some embryos injected with a REEP4 MO appear normal $\left(R^{\prime}\right)$ but in others, Islet1 expression is reduced. This phenotype is observed more frequently in embryos of $\mathrm{X}$. tropicalis $\left(T^{\prime}\right)$. embryos (Fig. 3F). Additional experiments showed that $1.2 \mathrm{ng}$ of $X$. tropicalis GFP-tagged REEP4 is able to rescue the effects of $30 \mathrm{ng}$ of MO2 injected into $X$. tropicalis (Fig. $3 \mathrm{H}, \mathrm{I})$. In such experiments, 35 out of 53 cases resembled the upper two embryos in Fig. 3 I and the remaining 14 resembled the lower embryo. The REEP4 construct used in the latter experiments does not include sequence complementary to $\mathrm{MO} 2$, which targets the 5' untranslated region of REEP4 (Fig. 3A).

\section{Down-regulation of neural markers in embryos lacking REEP4}

The inability of embryos lacking REEP4 to move in response to stimulation might be caused by defects in muscle development or nervous system development. To investigate this question we first studied the expression of several neural-specific genes by in situ hybridization. Markers of neural development such as $\mathrm{N}$-tubulin, Sox 3 and Pax6 were expressed normally at neurula stages in $X$. laevis embryos injected with REEP4 MO (Fig. 4A,B; E,F; I,J), and even at tailbud stages expression of all three genes was little reduced in embryos injected with the REEP4 MO (Fig. 4C,D; G,H; $\mathrm{K}, \mathrm{L})$. Neural crest formation, marked by expression Pax3, appeared normal at neurula stages (Fig. 4M,N), but was disrupted in tailbud embryos, especially in the somites and pronephros (Fig. $\mathrm{O}, \mathrm{P})$. At later stages, expression of the motor neuron marker Islet1 frequently appeared disripted in both $X$. laevis and $X$. tropicalis embryos injected with MOs directed against REEP4 (Fig. 4Q-T).

\section{Down-regulation of myogenic markers in embryos lacking REEP4}

We also analysed the expression of various myogenic regula- tory factors (Tapscott, 2005) and muscle terminal differentiation products in embryos injected with REEP4 MOs. Of the myogenic regulatory factors, Myf5 is expressed just before the onset of gastrulation and MyoD shortly thereafter (Chanoine and Hardy, 2003, Harvey, 1991, Hopwood et al., 1989, Hopwood et al., 1991). Mrf4 is expressed from late neurula stage 18 (Jennings, 1992). Later markers included 12/101, a monoclonal antibody which recognises an uncharacterised muscle-specific protein (Kintner and Brockes, 1984), dystrophin, which is a member of a multiprotein complex that links muscle cytoskeleton to the extracellular matrix (Hoffman et al., 1987), cardiac actin (Mohun et al., 1984) and myosin heavy chain (MHC) (Radice and Malacinski, 1989).

At neurula stages (prior to expression of Mrf4), Myf5 and MyoD proved to be expressed normally in $X$. laevis embryos injected with REEP4 MO (Fig. 5A,B; E,F). Expression of cardiac actin and $\mathrm{MHC}$ were also normal at neurula stages (Fig. $5 \mathrm{U}, \mathrm{V}$; $Y, Z$ ). However, by tailbud stages expression of many muscle markers was reduced or disrupted in embryos injected with REEP4 MO compared with embryos injected with control MO. In particular, somites frequently failed to form their normal chevron shape in embryos lacking REEP4 (Fig. 5C,D,G,H,K,L). The same disruption of somite morphology was also observed in embryos stained with monoclonal antibody $12 / 101$ (Fig. 5M-P) and with an antibody recognising dystrophin (Fig. 5Q-T). Expression of the terminal differentiation markers muscle-specific actin and myosin heavy chain was as normal at neurula stages in $X$. laevisembryos lacking REEP4 (Fig. 5U, $, Y, Z$ ) but significantly reduced by tailbud stages (Fig. 5W,X,AA,BB).

Expression of the 12/101 epitope was also reduced in embryos 

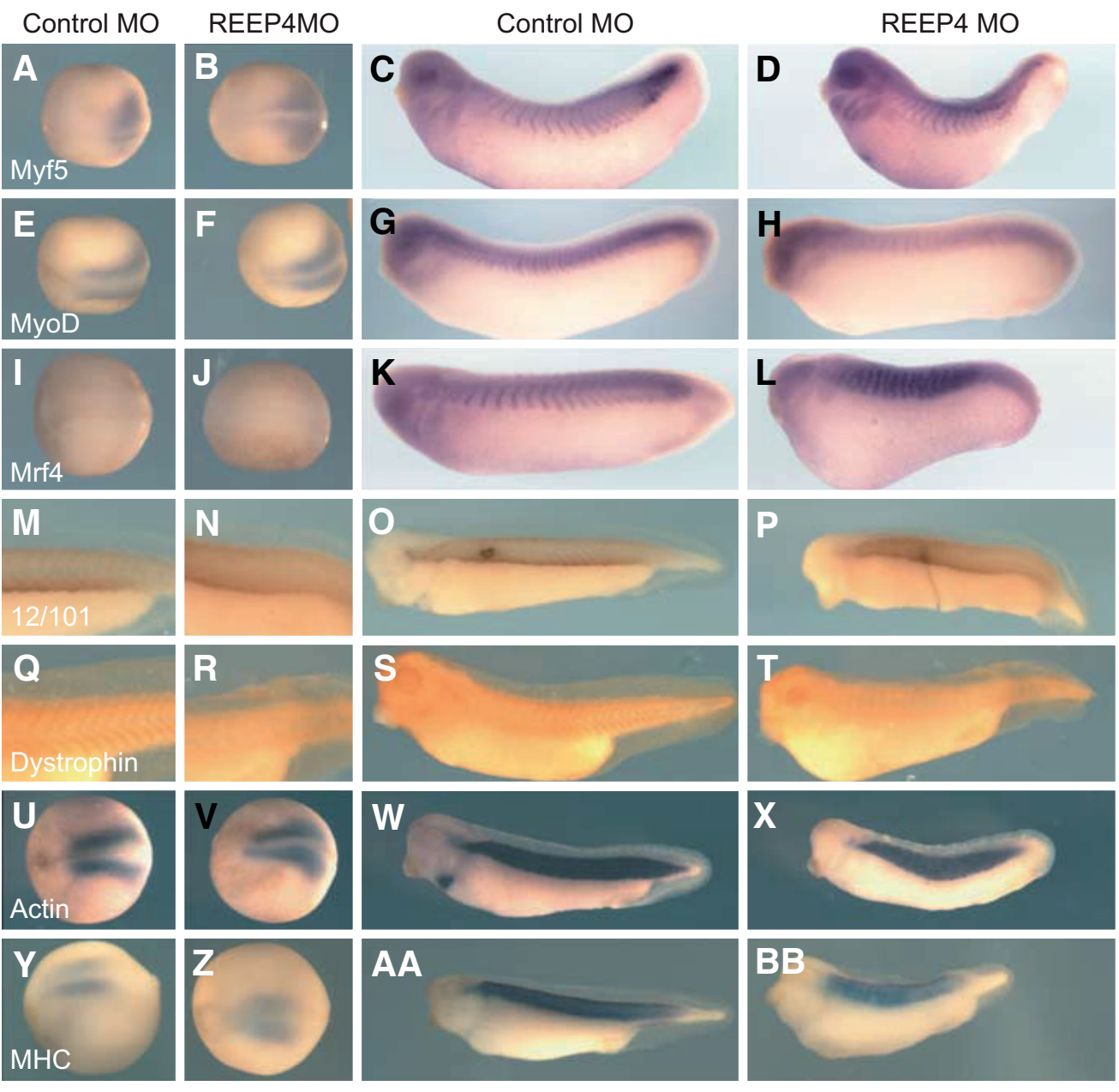

Control $\mathrm{MO}$

REEP 4 MO2

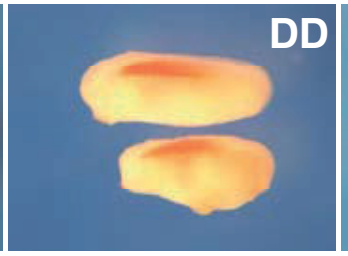

DD

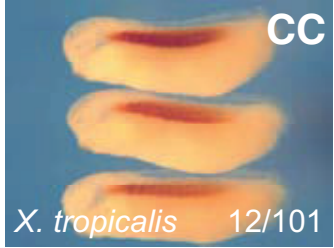

Control MO
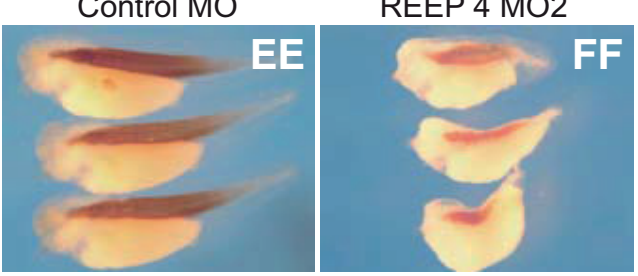

Fig. 5. Activation of muscle markers in embryos lacking REEP4 is normal during neurula stages but their expression becomes disorganised or reduced thereafter. $X$. laevis (A-BB) or $\mathbf{X}$. tropicalis (CC-FF) embryos were injected, respectively, with 90 ng MO or 30 ng MO2. Control embryos received the same amounts of control MO. They were cultured to neurula or tailbud stages and analysed by in situ hybridisation for expression of Myf5 MyoD, Mrf4, the 12/101 epitope, Dystrophin, Cardiac actin and Myosin Heavy Chain. Note in X. laevis that expression of markers at the neurula stage is normal $(A, B ; E, F ; U, V ; Y, Z)$ but that they become disorganised (C,D; G,H; $K, L ; O, P ; S, T)$ or reduced (W, X; $A A, B B)$ thereafter. The decrease in Cardiac actin expression in the heart in $\mathbf{( X )}$ is not a consistent observation. Expression of the 12/101 epitope in X. tropicalis is more sensitive to loss of REEP4 function than is expression in X. laevis. Note the decreased levels of 12/101 staining in (DD) compared with (P).

Xenopus laevis indicates that the impaired development of both begins at similar stages. We do note, however, that in $X$. tropicalis, REEP4 expression is stronger in somitic tissue than in the nervous system and that defects in muscle precede those in neural tissue. These observations suggest that in this species the primary defect is in muscle.

We know very little about the function of REEP 4 and how it might act. Like other members of the REEP family it plays a role in regulating the expression of cell surface

of $X$. tropicalis, especially in posterior regions, and, interestingly, in this species defects in muscle development preceded those observed in the nervous system (Fig. 5CC-FF and data not shown).

\section{Discussion}

Our results show that REEP4 is expressed at high levels in the unfertilised egg of the Xenopus embryo. Levels of REEP4 mRNA decline during cleavage stages, and after gastrulation and neurulation transcripts are then enriched in somites and neural tube. Loss of REEP4 function caused by injection of antisense morpholino oligonucleotides causes defects in these very tissues; although their early specification occurs normally, they fail to undergo proper morphogenesis and differentiation. It is possible that the failure of muscle differentiation exacerbates the degeneration of neural structures, or vice-versa, but our study in receptors. For example, human REEP1 and REEP3 increase the functional expression of the bitter taste receptor while REEPs 2 , 4 and 6 reduce it (Behrens et al., 2006). The bitter taste receptors are not known to be expressed in the early Xenopus embryo, although we have recently identified their Xenopusorthologues by BLAST searching (M. Gilchrist and JCS, unpublished). It is, of course, also possible that the REEPs affect the expression of other cell surface receptors; this has yet to be investigated.

Future work will focus on the mode of action of REEP4. We shall investigate the effects of removing maternal transcripts, and also search for receptors whose cell surface expression might be influenced by this protein. In addition, it may be interesting to explore potential links between REEP4, and the phenotype we observe in this paper, and hereditary spastic paraplegias (HSPs). Thus, mutations in REEP1 are the third most common cause of HSPs (Zuchner et al., 2006) after spastin (Hazan et al., 1999) and atlastin (Muglia et al., 2002, 
Zhao et al., 2001), and all three proteins are thought to play some role in membrane trafficking. The phenotypes of embryos lacking REEP4 suggest that it too may be involved in HSPs.

\section{Materials and Methods}

\section{REEP phylogenetic tree}

The REEP sequences were aligned using ClustalW at the EBI: http:/ /www.ebi.ac.uk/Tools/clustalw/index.html (Chenna et al., 2003). The phylogenetic tree was drawn using the output from Clustal W and the Phylip:drawtree software available at http://bioweb.pasteur.fr/seqanal/ interfaces/drawtree.html (Felsenstein, 1989) (version 3.5c distributed by the author and the Department of Genetics, University of Washington, Seattle, USA).

\section{Xenopus embryos and antisense morpholino oligonucleotides}

Embryos of Xenopus laevis and Xenopus tropicalis were obtained by in vitrofertilization and staged according to Nieuwkoop and Faber (1975). Antisense morpholino nucleotides (MO) were designed by and acquired from GeneTools (Philomath, OR, USA) (Fig 3A). The control MO was the standard control designed by GeneTools. Embryo manipulation and microinjection for $X$. laevis and for $X$. tropicalis were as described (Rana et al., 2006). Embryos were cultured at $14^{\circ} \mathrm{C}$ to midblastula stage 8 and were then transferred to $10 \%$ NAM (Slack, 1984).

REEP4 plasmid and in vitro transcription of antisense RNA probes

Clone Tegg010a23, containing a Xenopus tropicalis REEP4 cDNA in pCS107, was picked from the Gurdon Institute $X$. tropicalis cDNA collection. It was linearised with EcoRI and transcribed using T7 RNA polymerase. A Xenopus laevis REEP4 cDNA in the vector pCVM-SPORT6 was obtained from the I.M.A.G.E. Consortium (clone 6862296). It was linearised with Xhol and transcribed using T7 RNA polymerase.

\section{In vitro transcription-translation and western blotting}

The TNT Quick coupled transcription/translation system (Promega) was used according to the manufacturer's instructions using $100 \mathrm{ng} X$. tropicalis REEP4 RNA. For western blots, embryos were injected with 0.5 or 1.0. ng RNA encoding $X$. laevis REEP4 carrying a C-terminal HA tag, together with $90 \mathrm{ng} \mathrm{MO}$. Groups of ten embryos were collected at the gastrula stage and resuspended in $100 \mu$ l lysis buffer $(50 \mathrm{mM} \mathrm{pH} 7.5,150$ $\mathrm{mM} \mathrm{NaCl}, 1 \mathrm{mM}$ EDTA pH 8, 1\% Triton, protease inhibitors). One embryo equivalent was subjected to western blot analysis using 1:5000 anti-HAperoxidase (Roche).

RNA isolation and quantitative PCR. Total RNA was extracted from ten embryos for each developmental stage using TRIzol reagent (Invitrogen). Quantitative PCR was performed using the BioLabs SYBR Green qPCR kit with gene specific primers. A standard curve was prepared using a serial dilution of embryo RNA. PCR primers were:

forward 5'TGCTTGTCTTTGGTTTGCTG-3';

reverse 5'-AGGCTGGCTCCTCTTGTGTA-3'. Amplification conditions were: denaturing temperature: $95^{\circ} \mathrm{C}$; annealing temperature/time $60^{\circ} \mathrm{C} /$ $10 \mathrm{~s}$; extension temperature/time $70^{\circ} \mathrm{C} / 10 \mathrm{~s}$. Experiments were carried out three times. RNA levels were normalized to the level of ornithine decarboxylase (ODC) (Piepenburg et al., 2004).

\section{In situ hybridization and immunohistochemistry}

Whole-mount in situhybridization was performed as described (Harland, 1991) using DIG labelled probes and BM purple (Roche) as a substrate. $X$. laevis in situprobes made from I.M.A.G.E. clone plasmids were MRF4 (3200585), Pax3 (7981250) and Islet1 (4058863). X. tropicalis Islet1 (Tneu056008) was picked from the Gurdon Institute $X$. tropicalis cDNA library. Other probes included N-tubulin (Richter et al., 1988), Sox3 (Zygar et al., 1998), Pax6 (Hirsch and Harris, 1997), Myf5 (Hopwood et al., 1991), MyoD (Hopwood et al., 1989), Cardiac actin (Mohun et al., 1984), and Myosin Heavy Chain (Radice and Malacinski, 1989), the last of which was the kind gift of Dr Mike Zuber.

Whole-mount staining with monoclonal antibodies 12/101 (Kintner and Brockes, 1984) and dystrophin (Sigma, MADRA1) was carried out as described (Smith, 1993). Images were captured using Openlab software (Improvision). Some specimens were sectioned after staining. They were embedded in a gelatin/albumin mixture and solidified with glutaraldehyde. Sections $(30 \mu \mathrm{m})$ were cut on a Leica VT1000M vibrotome and mounted in $90 \%$ glycerol.

\section{Acknowledgements}

We thank our colleagues Kevin Dingwell, Anja Hagemann and Oliver Nentwich for their help and advice. We are also grateful to Nancy Papalopulu, Anna Philpott and Mike Zuber for in situ hybridisation probes, and Yung-Yao Lin for the dystrophin antibody. This work was supported by The Wellcome Trust and the BBSRC.

\section{References}

ALTSCHUL, S.F., MADDEN, T.L., SCHAFFER, A.A., ZHANG, J., ZHANG, Z., MILLER, W. and LIPMAN, D.J. (1997). Gapped BLAST and PSI-BLAST: a new generation of protein database search programs. Nucleic Acids Res 25: 33893402.

BEHRENS, M., BARTELT, J., REICHLING, C., WINNIG, M., KUHN, C. and MEYERHOF, W. (2006). Members of RTP and REEP gene families influence functional bitter taste receptor expression. J Biol Chem 281: 20650-20659.

BRANDS, A. and HO, T.H. (2002). Function of a plant stress-induced gene, HVA22. Synthetic enhancement screen with its yeast homolog reveals its role in vesicular traffic. Plant Physiol 130: 1121-1131.

CALERO, M., WHITTAKER, G.R. and COLLINS, R.N. (2001). Yop1p, the yeast homolog of the polyposis locus protein 1, interacts with Yip1p and negatively regulates cell growth. J Biol Chem 276: 12100-12112.

CASTERMANS, D., VERMEESCH, J.R., FRYNS, J.P., STEYAERT, J.G., VAN DE VEN, W.J., CREEMERS, J.W. and DEVRIENDT, K. (2007). Identification and characterization of the TRIP8 and REEP3 genes on chromosome 10q21.3 as novel candidate genes for autism. Eur J Hum Genet 15: 422-431.

CHANOINE, C. and HARDY, S. (2003). Xenopus muscle development: from primary to secondary myogenesis. Dev. Dyn. 226: 12-23.

CHENNA, R., SUGAWARA, H., KOIKE, T., LOPEZ, R., GIBSON, T.J., HIGGINS, D.G. and THOMPSON, J.D. (2003). Multiple sequence alignment with the Clustal series of programs. Nucleic Acids Res 31: 3497-3500.

CLARK, A.J., METHERELL, L.A., CHEETHAM, M.E. and HUEBNER, A. (2005). Inherited ACTH insensitivity illuminates the mechanisms of ACTH action. Trends Endocrinol Metab 16: 451-457.

FELSENSTEIN, J. (1989). PHYLIP - Phylogeny Inference Package (Version 3.2). Cladistics 5: 164-166.

GILCHRIST, M.J., ZORN, A.M., VOIGT, J., SMITH, J.C., PAPALOPULU, N. and AMAYA, E. (2004). Defining a large set of full-length clones from a Xenopus tropicalis EST project. Dev Bio/271: 498-516.

HARLAND, R.M. (1991). In situ hybridization: an improved whole-mount method for Xenopus embryos. Methods Cell Bio/36: 685-695.

HARVEY, R.P. (1991). Widespread expression of MyoD genes in Xenopus embryos is amplified in presumptive muscle as a delayed response to mesoderm induction. Proc. Nat. Acad. Sci. USA 88: 9198-9202.

HAZAN, J., FONKNECHTEN, N., MAVEL, D., PATERNOTTE, C., SAMSON, D., ARTIGUENAVE, F., DAVOINE, C.S., CRUAUD, C., DURR, A., WINCKER, P. et al. (1999). Spastin, a new AAA protein, is altered in the most frequent form of autosomal dominant spastic paraplegia. Nat Genet 23: 296-303.

HIRSCH, N. and HARRIS, W.A. (1997). Xenopus Pax-6 and retinal development. $\checkmark$ Neurobio/32: 45-61.

HOFFMAN, E.P., BROWN, R.H., JR. and KUNKEL, L.M. (1987). Dystrophin: the protein product of the Duchenne muscular dystrophy locus. Ce//51: 919-928.

HOPWOOD, N.D., PLUCK, A. and GURDON, J.B. (1989). MyoD expression in the forming somites is an early response to mesoderm induction in Xenopus embryos. EMBO J. 8: 3409-3417. 
HOPWOOD, N.D., PLUCK, A. and GURDON, J.B. (1991). Xenopus Myf-5 marks early muscle cells and can activate muscle genes ectopically in early embryos. Development 111: 551-560.

JENNINGS, C.G. (1992). Expression of the myogenic gene mrf4 during Xenopus development. Dev. Biol. 151: 319-332.

KINTNER, C.R. and BROCKES, J.P. (1984). Monoclonal antibodies identify blastemal cells derived from dedifferentiating limb regeneration. Nature 308: 67-69.

LAL, G. and GALLINGER, S. (2000). Familial adenomatous polyposis. Semin Surg Oncol18: 314-323.

MCDERMOTT, C., WHITE, K., BUSHBY, K. and SHAW, P. (2000). Hereditary spastic paraparesis: a review of new developments. I Neurol Neurosurg Psychiatry69: 150-160.

MOHUN, T.J., BRENNAN, S., DATHAN, N., FAIRMAN, S. and GURDON, J.B. (1984). Cell type-specific activation of actin genes in the early amphibian embryo. Nature 311: 716-721.

MUGLIA, M., MAGARIELLO, A., NICOLETTI, G., PATITUCCI, A., GABRIELE, A.L., CONFORTI, F.L., MAZZEI, R., CARACCIOLO, M., ARDITO, B., LASTILLA, M. et al. (2002). Further evidence that SPG3A gene mutations cause autosomal dominant hereditary spastic paraplegia. Ann Neuro/51: 794-795.

PIEPENBURG, O., GRIMMER, D., WILLIAMS, P.H. and SMITH, J.C. (2004). Activin redux: specification of mesodermal pattern in Xenopus by graded concentrations of endogenous activin B. Development 131: 4977-4986.

RADICE, G.P. and MALACINSKI, G.M. (1989). Expression of myosin heavy chain transcripts during Xenopus laevis development. Dev Bio/133: 562-568.

RANA, A.A., COLLART, C., GILCHRIST, M.J. and SMITH, J.C. (2006). Defining synphenotype groups in Xenopus tropicalis by use of antisense morpholino oligonucleotides. PLOS Genet 2: e193.
RICHTER, K., GRUNZ, H. and DAWID, I.B. (1988). Gene expression in the embryonic nervous system of Xenopus laevis. Proc. Nat. Acad. Sci. USA 85: 8086-8090.

SAITO, H., KUBOTA, M., ROBERTS, R.W., CHI, Q. and MATSUNAMI, H. (2004). RTP family members induce functional expression of mammalian odorant receptors. Cel/119: 679-691.

SHEN, Q., UKNES, S.J. and HO, T.H. (1993). Hormone response complex in a novel abscisic acid and cycloheximide-inducible barley gene. J Biol Chem268: 23652-23660.

SLACK, J.M. (1984). Regional biosynthetic markers in the early amphibian embryo. $\checkmark$ Embryol Exp Morpho/80: 289-319.

SMITH, J.C. (1993). Purifying and assaying mesoderm-inducing factors from vertebrate embryos. In Cellular Interactions in Development - a Practical Approach, (ed. HARTLEY, D.). Oxford University Press, Oxford, pp.181-204.

TAPSCOTT, S.J. (2005). The circuitry of a master switch: Myod and the regulation of skeletal muscle gene transcription. Development 132: 2685-2695.

ZHAO, X., ALVARADO, D., RAINIER, S., LEMONS, R., HEDERA, P., WEBER, C.H., TUKEL, T., APAK, M., HEIMAN-PATTERSON, T., MING, L. et al. (2001). Mutations in a newly identified GTPase gene cause autosomal dominant hereditary spastic paraplegia. Nat Genet 29: 326-331.

ZUCHNER, S., WANG, G., TRAN-VIET, K.N., NANCE, M.A., GASKELL, P.C., VANCE, J.M., ASHLEY-KOCH, A.E. and PERICAK-VANCE, M.A. (2006). Mutations in the novel mitochondrial protein REEP1 cause hereditary spastic paraplegia type 31. Am J Hum Genet 79: 365-369.

ZYGAR, C.A., COOK, T.L. and GRAINGER, R.M., JR. (1998). Gene activation during early stages of lens induction in Xenopus. Development 125: 3509-3519.

\title{
Further Related Reading, published previously in the Int. J. Dev. Biol.
}

See our recent Special Issue Fertilization, in honor of David L. Garbers and edited by Paul M. Wassarman and Victor D. Vacquier at: http://www.ijdb.ehu.es/web/contents.php?vol=52\&issue=5-6

\author{
Head-tail patterning of the vertebrate embryo: one, two or many unresolved \\ problems? \\ Claudio D. Stern, Jeroen Charité, Jacqueline Deschamps, Denis Duboule, Anthony J. \\ Durston, Marie Kmita, Jean-François Nicolas, Isabel Palmeirim, Jim C. Smith and \\ Lewis Wolpert \\ Int. J. Dev. Biol. (2006) 50: 3-15
}

\section{Making mesoderm—upstream and downstream of Xbra. \\ $J$ C Smith}

Int. J. Dev. Biol. (2001) 45: 219-224

Not a total waste of time. An interview with John Gurdon. James C Smith Int. J. Dev. Biol. (2000) 44: 93-99

From engineering to positional information to public understanding. An interview with Lewis Wolpert.

James C. Smith

Int. J. Dev. Biol. (2000) 44: 85-91

Follistatin expression in ES and F9 cells and in preimplantation mouse embryos. R M Albano and J C Smith Int. J. Dev. Biol. (1994) 38: 543-547

2006 ISI **Impact Factor $=3.577^{* *}$

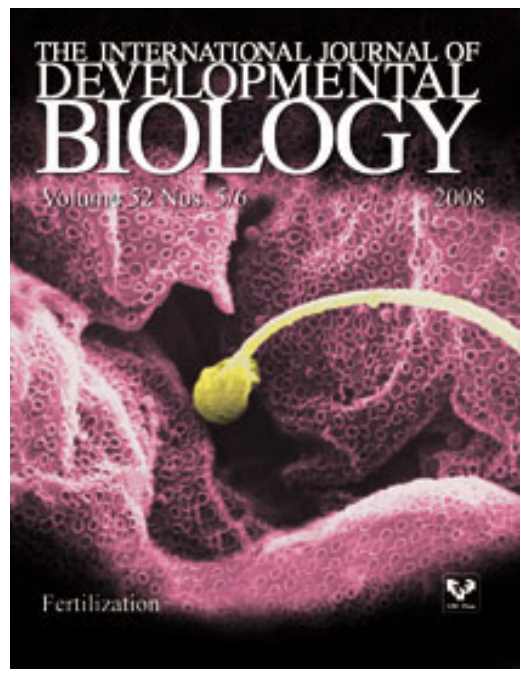

